\title{
ANNOUNCEMENTS
}

\section{3rd International Congress}

\section{The Immune Consequences of Trauma, Shock and Sepsis - Mechanisms and Therapeutic} Approaches

Munich, Germany 2-5 March 1994

The deadline for abstracts is October 30, 1993

Further information from:

Dr Eugen Faist,

Ludwig-Maximilians-Universität Munich,

Klinikum Grosshadern,

Dept. of Surgery,

Marchioninistrasse 15

8000 Munich 70, Germany

Tel: 49-89-7095-3441

49-89-7095-3436

Fax: 49-89-7095-2460

\section{International Conference on Melioidosis: \\ Prevailing problems and future directions}

7th-8th April 1994

Kuala Lumpur, Malaysia

Topics will include:

Epidemiology; Virulence and pathogenesis; Clinical aspects; Immunological aspects; Diagnosis;

Management and therapy; Role of new antimicrobial agents; Veterinary aspects; Prevention.

Faculty will comprise international authorities from Australia, Canada, South-East Asia, UK and USA.

Registration fee: US\$200

For further details, please contact: Dr Faridah Moosdeen / Dr S.D. Puthucheary

Department of Medical Microbiology

Universiti Kebangsaan Malaysia

P.O. Box 12418

50778 Kuala Lumpur, Malaysia.

Tel: (60 3) $4405527 \quad$ Fax: (60 3) 2929039.

\section{International Conference on Biomedical Periodicals}

June 16th-18th 1994

Beijing, China

This conference, organised by the Chinese Medical Association, will have as its themes quality control and the future of biomedical journals. Topics will include peer review and quality control; ISO standards and biomedical journals; editorial policy and selection of contents; ethics and legal responsibilities of authors and editors; administration and economics; development and future of scientific journals.

Various social and cultural events will be arranged during the conference and two optional tours will be available after the meeting.

For further information, please contact: Dr Jiang Yongmao, Secretary of the Organizing Committee, Chinese Medical Association, 42 Dongsi Xidajie, Beijing 100710, China. Tel: 5133311 ext. 362. Fax: (861) 5123754. 